\title{
Research report \\ Effects of adult dysthyroidism on the morphology of hippocampal neurons
}

\author{
Josefina Sala-Roca ${ }^{\mathrm{c}, *}$, Eva Estebanez ${ }^{\mathrm{d}}$, Ferran Balada ${ }^{\mathrm{a}}$, \\ Adriana Garau ${ }^{\mathrm{b}}$, Maria Assumpció Martí-Carbonell ${ }^{\mathrm{a}}$ \\ ${ }^{a}$ Department of Psychobiology, Universitat Autònoma de Barcelona, Spain \\ ${ }^{\mathrm{b}}$ Department of Basic Psychology, Universitat Autònoma de Barcelona, Spain \\ ${ }^{\mathrm{c}}$ Department of Pedagogy, Universitat Autònoma de Barcelona, Spain \\ d Biochemistry \& Biophysics, San Francisco University, USA
}

Received 14 June 2007; received in revised form 6 November 2007; accepted 24 November 2007

\begin{abstract}
This study investigates the effect of thyroid hormones on the morphology of hippocampal neurons in adult rats. Hypo- and hyperthyroidism were induced by adding $0.02 \%$ methimazole and $1 \% \mathrm{~L}$-thyroxine, in drinking water from 40 days of age, respectively. When the rats were 89 days old their brains were removed and stained by a modified Golgi method and blood samples were collected in order to measure T4 serum levels. Neurons were selected and drawn using a camera lucida.

Our results show that methimazole administration reduces the dendritic branching of the apical shafts of CA3 and CA1 pyramidal neurons manly by increasing the distance to the first branch point in both types of neurons, and reducing branch points in the radius of $50 \mu \mathrm{m}$ from the soma in CA1 neurons. Nevertheless, it was observed an increase of apical spine density in CA3 neurons from this group.

Thyroxine reduces apical and basal tree of CA3 pyramidal neurons increasing the distance to the first branch point, reducing branch points in the radius of $50 \mu \mathrm{m}$ from the soma and increases their apical and basal spine density. In CA1 field, thyroxine reduces the number of basal branch points.

Both treatments seems to provoke alterations in the same direction reducing the dendritic branching and increasing spine density, although no significances appeared in some of the parameters analyzed. The effects are more evident in thyroxine than methimazole group; and in CA3 neurons than in CA1 neurons. In discussion it is pointed that the increase of spine density could be a mechanism to compensate the functionality reduction that can be provoke by the treatment effect on dendritic branching.
\end{abstract}

(C) 2007 Published by Elsevier B.V.

Keywords: Hypothyroidism; Hyperthyroidism; Hippocampus; Pyramidal neurons; Spine; Rats

\section{Introduction}

Thyroid hormones are essential for normal brain function. The hippocampus is a neural structure highly sensitive to the actions of thyroid hormones due to its high content of thyroid hormone receptors $[29,41]$. The most significant and specific regions of the hippocampus are: dentate gyrus, CA3 and CA1. Cells of dentate gyrus project, via mossy fibbers, upon dendrites of pyramidal cells of CA3. At the same time these cells

* Corresponding author at: Dep. Pedagogia Sistemàtica i Social, Univ. Autònoma de Barcelona, 08193 Bellaterra, Catalonia, Spain.

Tel.: +34935813188; fax: +34935811419.

E-mail address: fina.sala@uab.es (J. Sala-Roca). contribute to major input system to CA1 (the Schaffer collaterals). This circuit is implicated in different functions, i.e. in learning process and stress $[4,23,34,40]$.

Different studies have analyzed the effect of hypothyroidism in the development of the hippocampus. These studies have indicated that neonatal hypothyroidism decreases the weight of the hippocampus [25], decreases the volume and structure of granular and pyramidal neurons $[24,32,33]$, delays synaptogenesis [31], affects neuroblast migration [30], increases neuronal death [25] and reduces the number of synapses between mossy fibber and CA3 pyramidal neurons and the excrescences of CA3 pyramidal neurons [24].

In adulthood, hypothyroidism also decreases the weight of the hippocampus $[25,26]$ and the volume of the pyramidal 


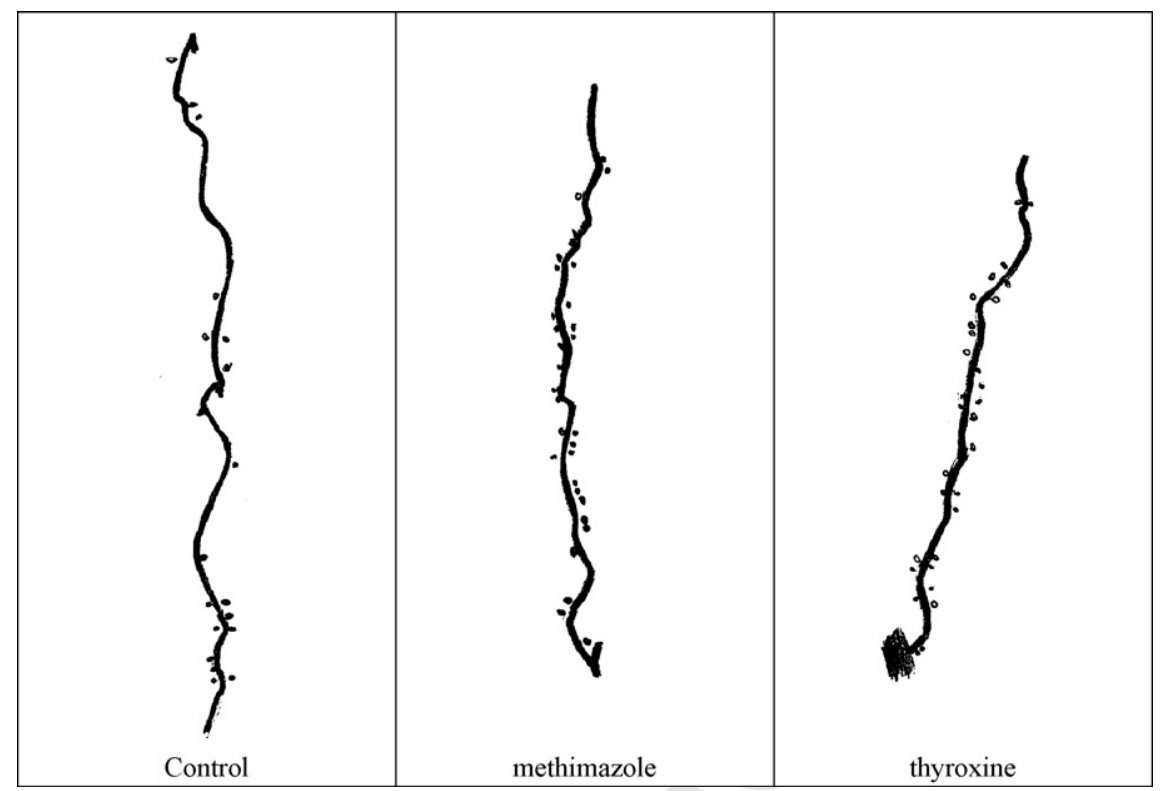

Fig. 1.

neurons in CA3 and CA1 [26]. However, only in CA1 the total number of pyramidal neurons was reduced by adult hypothyroidism [26]. Nevertheless, Alva-Sánchez et al. [2] found that hypothyroidism reduce the density of pyramidal neurons in CA3 region, and pointed out that the total number of pyramidal neurons in this area would be reduced. Montero-Pedrazuela et al. [27] found that short-term adult-onset hypothyroidism impairs dendritic arborization of immature neurons.

The effects of neonatal hyperthyroidism on the hippocampus have been less studied. Gould et al. [17] injected subcutaneously T3 to male and female rat pups on postnatals days 2 and 4 . At 2 months of age it was found an increase of the number and extension of dendrites, the branching points and thorny spines in pyramidal neurons of CA3 field. In CA1 field, hyperthyroidism only affected pyramidal neurons by increasing apical and basal spine density [17]. Other studies [20-22,37] indicate that neonatal hyperthyroidism produces the hyperplasia of intraand infrapyramidal mossy fibbers.

On the other hand, adult hyperthyroidism effects on the hippocampus are even more poorly understood. Gould et al. [18] injected T3 during five consecutive days to adult female rats. They found that apical and basal spine density of pyramidal neurons in CA1 field was decreased but the size of their cell body was not affected. Furthermore, neither the size of cell body, nor spine density were affected by hyperthyroidism in the CA3 field. In their study, they pointed out that the difference in responsiveness between CA1 and CA 3 indicates that adult CA1 pyramidal neurons inherently possess a greater degree of structural plasticity than do adult CA3 pyramidal neurons [18].

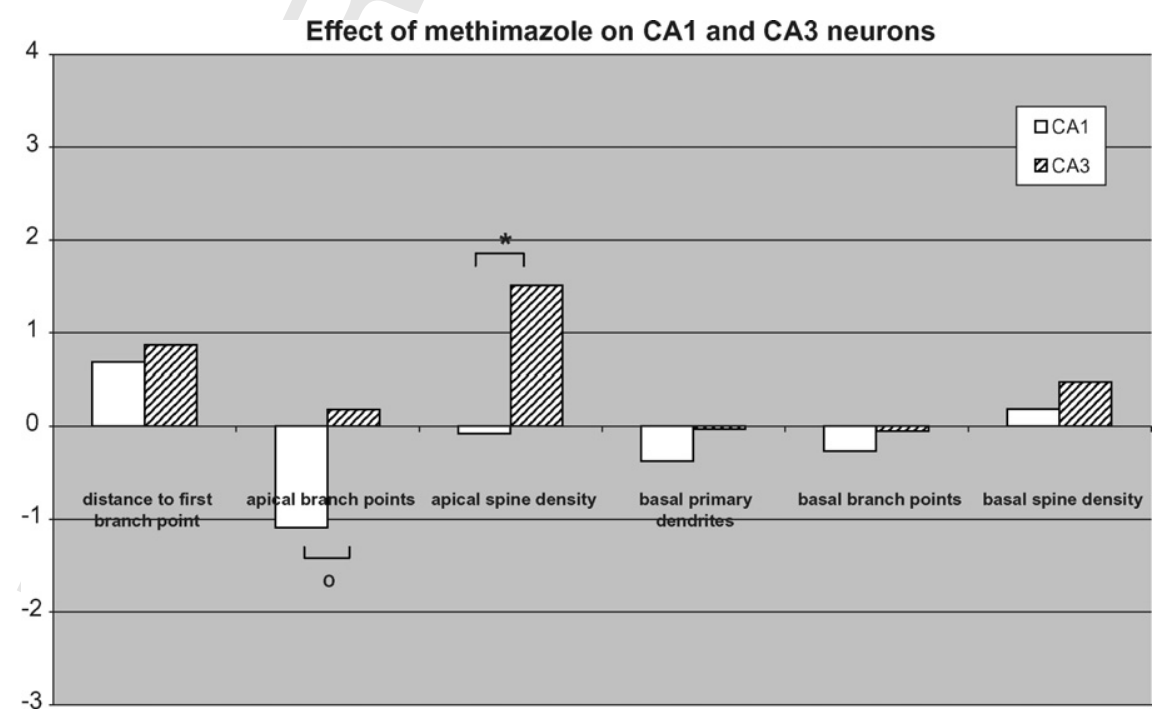

Fig. 2. Effect of methimazole on $\mathrm{CA} 1$ and $\mathrm{CA} 3$ neurons. 


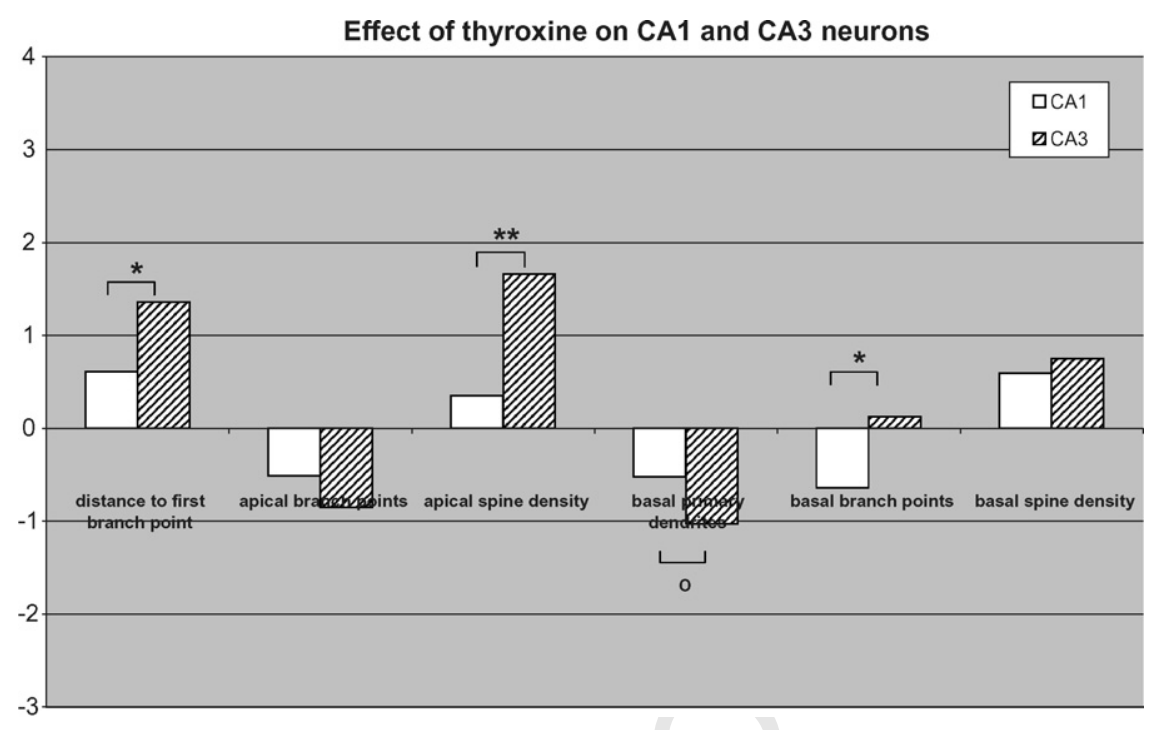

Fig. 3. Effect of thyroxine on $\mathrm{CA} 1$ and $\mathrm{CA} 3$ neurons.

To our knowledge, there are no studies that analyze the effects of permanent adult hyperthyroidism on morphological structure of pyramidal neurones. Moreover, the effects of adult hypothyroidism have only been analyzed by Madeira et al. as stated above [24-26]. Our study aims to investigate the effect of thyroid hormones on the morphology of hippocampal neurons in adult rats.

\section{Materials and methods}

\subsection{Subjects}

Subjects were 21 males (seven control, seven hypothyroid and seven hyperthyroid) Wistar rats bred in our laboratory. At 40 days of age rats were individually housed with ad libitum access to food and water. They had a light-dark circadian rhythm of $12 \mathrm{~h}$ (LP, 08:00-20:00 h). The temperature was regulated between $22 \pm 2{ }^{\circ} \mathrm{C}$ and the humidity between 40 and $60 \%$.

\subsubsection{Chemical induction of hypo- and hyperthyroidism}

Subjects were randomly allocated into the experimental groups. Treatment was administered via drinking water from 40 days of age until the end of the experiment, when the rats reached 89 days of age. The onset of puberty in male rats is around 40 days old $[6,12,19,28]$. Important changes in thyroid function occur during puberty as an adaptation to body and sexual development [14]. Hypothyroidism was induced by adding methimazole $(20 \mathrm{mg} / 100 \mathrm{ml})$ into the drinking water and hyperthyroidism was induced introducing L-thyroxine $(1 \mathrm{mg} / 100 \mathrm{ml})$ into the drinking water $[9,35,36]$. Methimazole prevent the coupling and iodination of tyrosine obstructing T4 and T3 synthesis.

This procedure were used in other studies and their efficiency inducing hypoand hyperthyroidism were proved testing TSH, T4 and T3 levels [8,3].

\section{Procedure}

When the rats were 89 days of age their brains were removed and stained by a modified Golgi method as described by Gabott and Somogyi [15]. Slices (150 $\mu \mathrm{m}$ thick) of the hippocampus were obtained with a slicing microtome. A minimum of one neurons and a maximum of five neurons $($ mode $=3$ ) per subject in each hippocampal region were drawn individually. As a whole 119 neurons (45 control, 31 hypothyroid and 43 hyperthyroid) were drawn individually at $625 \times$, using a camera lucida (Nikon, mod Drawing tubeL). Dendrites and dendritic spines were drawn at $1552.5 \times$ magnification.

In order to evaluate the morphological parameters we use the procedure of Gould et al. [17,42]. So the parameters evaluated were: distance from soma to the first branch point in apical dendrite, number of apical and basal primary dendrites, number of apical and basal branch points, and apical and basal dendritic spine density.

Thyroid hormone levels were measured in order to establish the degree of hypo- or hyperthyroidism induced by our treatment.

The experimental protocol was in agreement with the European Community Council Directive (EEC directive 86/609) for the care and use of laboratory animals and was therefore approved by the Ethical Committee on Animal and Human Experimentation of the Universitat Autònoma de Barcelona (Fig. 1).

\section{Statistics}

The data was analyzed using a commercial statistical package (SPSS/PC+). Analysis of variance (ANOVA) and $T$-test were performed to detect differences between control and each treated groups in T4 levels and in morphological parameters between. In order to facilitate the visual interpretation of differences in the morphological parameters that have different magnitudes, data are represented in Figs. 2 and 3 using Cohen's $d$ standardization [7].

\section{Results}

\subsection{Effect of methimazole treatment}

Differences in plasmatic levels of T4 confirmed that the treatment was effective in reducing thyroid hormone levels. $T$-Test shows that the methimazole group had reduced T4 
Table 1

Effect of hypothyroidism on pyramidal dendrites of CA3 and CA1

\begin{tabular}{llcr}
\hline & Parameter & Methimazole group (mean \pm S.E.M.) & Control group (mean \pm S.E.M.) \\
\hline CA3 & & & \\
Api- & Distance to the first branch point & $12.86 \pm 1.28^{*}$ & $9.38 \pm 0.89$ \\
cal & Branch points in the first $50 \mu$ & $3.29 \pm 0.92$ & $2.89 \pm 0.46$ \\
tree & Spines & $2.66 \pm 0.57^{* *}$ & $0.82 \pm 0.21$ \\
Basal & Primary dendrites & $3.80 \pm 0.39$ & $3.84 \pm 0.28$ \\
tree & Branch points in the first $50 \mu \mathrm{m}$ & $7.90 \pm 1.03$ & $8.10 \pm 1.01$ \\
& Spines & $5.36 \pm 1.55$ & $1.56 \pm 0.23$ \\
CA1 & & & $18.25 \pm 1.68$ \\
Api- & Distance to the first branch point & $18.52 \pm 2.68^{*}$ & $4.6 \pm 2.89$ \\
cal & Branch points in the first $50 \mu \mathrm{m}$ & $1.9 \pm 0.62^{*}$ & $4.24 \pm 0.87$ \\
tree & Spines & $4.07 \pm 1.07$ & $3.54 \pm 0.26$ \\
Basal & Primary dendrites & $3.12 \pm 0.22$ & $11.04 \pm 0.73$ \\
tree & Branch points in the first $50 \mu \mathrm{m}$ & $9.88 \pm 4.85$ & $2.92 \pm 0.61$ \\
& Spines & $3.49 \pm 0.81$ & \\
\hline
\end{tabular}

Significances are calculated respect control group. ${ }^{*} P<0.05 ; * * P=0.001$.

levels (control group $X=5.9 \pm 0.4 \mu \mathrm{g} / \mathrm{dl}$; methimazole group $X=1.2 \pm 0.3 \mu \mathrm{g} / \mathrm{dl} ;(t=6.7$, d.f. $=26 ; P<0.001)$.

\subsubsection{Pyramidal neurons of CA3}

The apical tree structure of neurons from the methimazole group was slightly affected: The distance between the soma and the first branch point was increased by methimazole treatment $(F(1,28)=5.08, P<0.05)$. Nevertheless, the most important effect of this treatment was over apical spine density. This parameter was increased in this experimental group in relation to the control group $(F(1,21)=14.19 ; P<0.001)$. So methimazole group in this variable has an average percentile of 93.3 respect of the average control group. The other apical and basal parameters were not affected.

\subsubsection{Pyramidal neurons of CAI}

Methimazole administration affects the structural tree of the CA1 neurons but not their spine density: Pyramidal neurons of methimazole group have a longer distance between soma and the first apical branch point $(F(1,34)=4.32 ; P<0.05)$, and fewer apical branch points in the $50 \mu \mathrm{m}$ radius $(F(1,28)=7.02$; $P<0.05)$. It was not observed any statistical significant differences in the basal tree (Table 1).

\subsection{Effect of thyroxine treatment}

Differences in plasmatic T4 levels confirmed that the treatment was effective in inducing hyperthyroxinemia. $T$-Test shows that the thyroxine group had increased T4 levels (control group $X=5.9 \pm 0.4 \mu \mathrm{g} / \mathrm{dl}$; thyroxine group $X=20.66 \pm 2.63 \mu \mathrm{g} / \mathrm{dl}$; $t=-7.9$, d.f. $=26, P<0.001)$.

\subsubsection{Pyramidal neurons of $C A 3$}

The effects of thyroxine administration on the structural tree were more evident than in methimazole administration. Neurons of thyroxine group in relation to control group have: a longer distance between the soma and the first apical branch point $(F(1,34)=17.07 ; P<0.001)$, fewer apical branch points in the $50 \mu \mathrm{m}$ radius $(F(1,31)=5.78 ; P<0.05)$, and fewer basal primary dendrites $(F(1,33)=9.11 ; P<0.01)$. On the contrary, thyroxine increase both, apical $(F(1,29)=21.99 ; P<0.001)$ and basal $(F(1,35)=5.25 ; P<0.05)$ spine density significantly. In apical spine density, thyroxine group has an average percentile of 95 respect of the average control group.

\subsubsection{Pyramidal neurons of $C A 1$}

Thyroxine administration modifies the structural tree: neurons of thyroxine group have a longer distance between soma and the first apical branch point and fewer basal primary dendrites - although these effects did not reach a significant level, these differences are closer to statistical $(F(1,39)=3,81 ; P=0.06$ and $F(1,44)=3.06 ; P=0.09)-$ and fewer basal branch points in the $50 \mu \mathrm{m}$ radius $(F(1,44)=4.79 ; P<0.05)$. Thyroxine administration increase the basal spine density, but this effect did not reach the significant level $(F(1,39)=3.63 ; P=0.06)$ (Table 2$)$.

\subsection{Vulnerability of CA1 AND CA3}

In order to observe the differences in vulnerability of pyramidal neurons of CA1 and CA3 to dysthyroidism, we compared the increase or decrease in the parameters analyzed respect to the control group in both areas. Results show that the effects of both treatments over CA1 and CA3 areas go globally in the same direction.

Methimazole (Fig. 2) increases apical spines $(t=-4.09$; d.f. $=13 ; P<0.01)$ in CA3 but not in CA1. There is a reduction of apical branch point in CA1 only (this difference is near to statistical signification, $t=-2.44$; d.f. $=15 ; P=0.06$ ).

Thyroxine (Fig. 3) also affects more CA3 than CA1 and this effect is more evident in apical zones. Thyroxine affects more CA3 than CA1 in the distance to the first branch $(t=-2.30$; d.f. $=34 ; P<0.05$ ); the number or primary dendrites (this dif- 
Table 2

Effect of hyperthyroidism on pyramidal dendrites of CA3 and CA1

\begin{tabular}{|c|c|c|c|}
\hline & Parameter & Control group (mean \pm S.E.M.) & Thyroxine group (mean \pm S.E.M.) \\
\hline \multicolumn{4}{|l|}{$\overline{\mathrm{CA} 3}$} \\
\hline \multirow[t]{3}{*}{ Apical tree } & Distance to the first branch point & $9.38 \pm 0.89$ & $16.08 \pm 1.43^{* * *}$ \\
\hline & Branch points in the first $50 \mu \mathrm{m}$ & $2.89 \pm 0.46$ & $1.40 \pm 0.39 *$ \\
\hline & Spines & $0.82 \pm 0.21$ & $3.91 \pm 0.64 * * *$ \\
\hline \multirow[t]{3}{*}{ Basal tree } & Primary dendrites & $3.84 \pm 0.28$ & $2.69 \pm 0.25^{* *}$ \\
\hline & Branch points in the first $50 \mu \mathrm{m}$ & $8.10 \pm 1.01$ & $8.56 \pm 0.73$ \\
\hline & Spines & $1.56 \pm 0.23$ & $2.62 \pm 0.41 *$ \\
\hline \multicolumn{4}{|l|}{ CA1 } \\
\hline \multirow[t]{3}{*}{ Apical tree } & Distance to the first branch point & $12.25 \pm 1.68$ & $17.44 \pm 2.07$ \\
\hline & Branch points in the first $50 \mu \mathrm{m}$ & $4.6 \pm 2.89$ & $2.75 \pm 0.93$ \\
\hline & Spines & $4.24 \pm 0.87$ & $5.60 \pm 1.14$ \\
\hline \multirow[t]{3}{*}{ Basal tree } & Primary dendrites & $3.54 \pm 0.26$ & $2.95 \pm 0.20$ \\
\hline & Branch points in the first $50 \mu \mathrm{m}$ & $11.04 \pm 0.73$ & $8.41 \pm 0.97 *$ \\
\hline & Spines & $2.92 \pm 0.61$ & $5.23 \pm 1.07$ \\
\hline
\end{tabular}

Significances are calculated respect control group. $* P<0.05$; $* * P<0.01 ; * * * P<0.001$.

ferences is near to statistical signification, $t=-2.15$; d.f. $=33$; $P=0.08)$; spines $(t=-3.80$; d.f. $=30 ; P<0.01)$; and basal primary dendrites (this differences is near to statistical signification, $t=1.92$; d.f. $=36 ; P=0.06$ ). The exception is basal branch points that are more affected in CA1 than CA3 $(t=-2.40$; d.f. $=36$; $P<0.05$ ).

The effects of thyroxine treatment over morphological variables were greater in CA3 than CA1. In CA3 all the variables analyzed, except basal branch points, presents an average percentile greater than 75 in reference to the average control group, whereas in CA1 all the average percentile for thyroxine group was between 64 and 73 .

\section{Discussion}

The increase in spine density could be the most relevant result observed in this study. This effect can be observed in methimazole and, especially, thyroxine treatment and it can be observed in both, CA3 and CA1 fields, although it is only significant in CA3 field. These results are surprising because they could indicate that both treatments increase hippocampal functionality. In fact several studies have shown that neonatal thyroxine treatment produces the hyperplasia of mossy fibbers [20-22,37].

Gould et al. [17,18] observed that adult hyperthyroidism results in a decrease of dendritic spine density in CA1, but not in CA3. Our results are in disagreement with those obtained by Gould et al. [18]. These authors induced an acute hyperthyroidism in adult female rats while in our study we have used a longer treatment in male rats. So the differences in the results can be explained in terms of different type of treatment and sex differences. In fact, Madeira et al. [26] found sexual differences in the effect of hypothyroidism over pyramidal neurons. Other authors have found different effects after short (8 days) and prolonged (30 days) hypothyroidism [5].

In methimazole treated rats, an increase of spine density was also observed in CA3 neurons. This observation is in agreement with what Madeira and Paula-Barbosa [24] described, namely that adult hypothyroidism increases the numerical density of synapses with mossy fibbers. Since dendritic spines are thought to be postsynaptic sites, it is likely that changes in spine density reflect changes in synaptic density. Over $95 \%$ of excitatory synapses on neurons occur on the dendritic spines, with each spine head typically receiving one synapse [13]. It must be taken into account that studies that are based on counting fixed spines might underestimate dynamic changes on spine density [38].

However, the spine density increase should not be analyzed in isolation. Both treatments also affect the dendritic branching. So thyroxine administration seems to reduce dendritic branching of the apical shafts mainly increasing the distance to the first branch point, but this effect was only significant in the CA3 field, where also reduces apical branch points in the first $50 \mu \mathrm{m}$. Hyperthyroidism also affects the dendritic branching of the basal shafts. Regarding control group, thyroxine group has fewer basal primary dendrites in CA3 field and fewer basal branch points in CA1 field.

Methymazole administration has effects similar to those of thyroxine treatment, but these effects are less significant. Thus adult hypothyroidism seems to reduce the dendritic branching of the apical shafts of CA3 and CA1 pyramidal neurons, mainly increasing the distance to the first branch point. The total dendritic branching is more reduced in CA1 than in CA3 neurons due to the fact that the apical branch points in the first $50 \mu \mathrm{m}$ were more reduced too.

Madeira et al. [26] found that thyroid hormone deficiency starting either neonatally or during maturity leads to a decrease in the total number of pyramidal neurons in CA1 but not in $\mathrm{CA} 3$ region. They concluded that hypothyroidism induces small alterations in the structural organization of the hippocampal CA3 region, contrary to what happens in CA1 in which neuronal death occurs. Our results are in agreement with Madeira and co-workers, and considering that in CA1 there is no increase of spine density, the functionality reduction would be more severe in CA1 than in CA3 hippocampal area. 
The minor effects of methimazole treatment could be surprising since in animal studies carried out by our and others groups $[9,10,35,36]$ show that behavioural effects are more important in hypothyroidism than in hyperthyroidism. Nevertheless, it must be taken into account that other variables affected by dysthyroidism, not included in this study, are relevant in order to explain behavioural changes. For example, some authors have found that adult hippocampus neurogenesis is affected by hypothyroidism $[1,11,27]$ but not by hyperthyroidism [11].

According to the above mentioned, the increase of spine density could be one mechanism to compensate the branching reduction and the loss of neurons. Nevertheless, this effect would be evident in CA3 field. In fact, different studies have shown that thyroid manipulation affects mossy fibbers, the major input of pyramidal neurons in CA3 [20-22,37]. We do not know if a similar effect has been described in Schaffer fibbers, the major input of pyramidal neurons in CA1. However, Gerges et al. [16] found that hypothyroidism impairs the expression of E-LTP in the Schaffer collateral synapses. Sunanda et al. [39] found that stress induces dendrite atrophy, and increase apical and basal spines in CA3. These authors pointed out that this increase of spines could be interpreted as a compensation mechanism for the loss of the dendritic extension or as the increase of the activity of glutamatergic system. Both possibilities could explain our results.

In conclusion, (1) both, methimazole and thyroxine treatment affect pyramidal neuron morphology. (2) Treatments provoke alterations in the same direction: reduction of some parameters of dendritic branching and increase of spine density. (3) This reduction in dendritic branching and the increase of spine density is more evident in thyroxine than methimazole group. (4) The effects are more evident in CA3 neurons. However, the increase spines in this field could be a compensatory effect to prevent the lost of functionality caused by the dendritic branching reduction.

\section{References}

[1] Ambrogini P, Cuppini R, Ferri P, Manzini C, Ciaroni S, Voci A, et al. Thyroid hormones affect neurogenesis in the dentate gyrus of adult rat. Neuroendocrinology 2005;81:244-53.

[2] Alva-Sanchez C, Oriz-Butron R, Pacheco-Rosado J. Kainic acid does not affect CA3 hippocampal region pyramidal cells in hypothyroid rats. Brain Res Bull 2004;63(2):167-71.

[3] Berbal P, Guadaño-Ferraz A, Angulo A, Cerezo JR. Role of thyroid hormones in the maturation of interhemispheric connections in rats. Behav Brain Res 1994;64:9-14.

[4] Buckley MJ. The role of the perirhinal cortex and hippocampus in learning, memory, and perception. Q J Exp Psychol B-Comp Physiol Psychol 2005;58(3-4):246-68.

[5] Calza L, Aloe L, Giardino L. Thyroid hormone-induced plasticity in the adult rat brain. Brain Res Bull 1997;44(4):549-57.

[6] Chappel SC, Ramaley JA. Changes in the isoelectric focusing profile of pituitary follicle-stimulating hormone in the developing male rat. Biolol Reprod 1985;32:567-73.

[7] Cohen J. Statistical power analysis for the behavioral sciences. 2nd ed. Hillsdale, NJ: Lawrence Earlbaum Associates; 1988.

[8] Darbra S. Alteracions de l'eix tiroidal: Efectes conductuals i morfològics. Doctoral thesis. Barcelona; 1994.

[9] Darbra S, Balada F, Garau A, Gatell P, Sala J, Martí-Carbonell MA. Perinatal alterations of thyroid hormones and behaviour in adult rats. Behav Brain Res 1995;68:159-64.
[10] Darbra S, Garau A, Balada F, Sala J, Martí-Carbonell MA. Perinatal hypothyroidism effects on neuromotor competence, novelty-directed exploratory and anxiety-related behaviour and learning in rats. Behav Brain Res 2003;143:209-15.

[11] Desouza LA, Ladiwala U, Daniel SM, Agashe S, Vahadilla RA, Vahadilla VA. Thyroid hormone regulates hippocampal neurogenesis in the adult rat brain. Mol Cell Neurosci 2005;29:414-26.

[12] Engelbregt MJ, Houdijk ME, Popp-Snijders C, Delemarre-van de Waal HA. The effects of intra-uterine growth retardation and postnatal undernutrition on onset of puberty in male and female rats. Pediatr Res 2000;48(6):8037.

[13] Fiala JC, Spacek J, Harris KM. Dendritic spine pathology: cause or consequence of neurological disorders? Brain Res Rev 2002;39:29-54.

[14] Fleury Y, Van Melle G, Woringer V, Gaillard RC, Portmann L. Sexdependent variations and timing of thyroid growth during puberty. J Clin Endocrinol Metab 2001;86(2):750-4.

[15] Gabott PL, Somogyi J. The 'single' section Golgi impregnation procedure: methodological description. J Neurosci Methods 1984;11:221-30.

[16] Gerges NZ, Stringer JL, Alkadhi KA. Combination of hypothyroidism and stress abolishes early LTP in the CA1 but not dentate gyrus of hippocampus of adult rats. Brain Res 2001;922(2):250-60.

[17] Gould E, Westlind-Dabielson A, Tranfot M, McEwan BS. Sex differences and thyroid hormone sensitivity of hippocampal pyramidal cells. J Neurosci 1990;10(3):996-1003.

[18] Gould E, Allan MD, Mc Ewen BS. Dendritic spin density of adult hippocampal pyramidal cells is sensitive to thyroid hormone. Brain Res 1990;525:327-9.

[19] Korenbrot CC, Huhtaniemi IT, Weiner RI. Preputial separation as an external sign of pubertal development in the male rat. Biol Reprod 1977;17:298-303.

[20] Lauder JM, Mugnaini E. Infrapyramidal mossy fibbers in the hippocampus of the hyperthyroid rat. Dev Neurosci 1980;3:248-65.

[21] Lauder JM, Mugnaini E. Early hyperthyroidism alters the distribution of mossy fibbers in the rat hippocampus. Nature 1977;268:335-7.

[22] Lipp HP, Schwegler H, Crusio WE, Wolfer DP, Leisinger-Trigona MC, Heimrich B, et al. Using genetically-defined rodent strains for the identification of hippocampal traits relevant for two-way avoidance learning: a non-invasive approach. Experientia 1989;45:845-59.

[23] Lucassen PJ, et al. Stress, depression and hippocampal apoptosis. CNS Neurol Disord Drug Targets 2006;5(5):531-46.

[24] Madeira MD, Paula-Barbosa MM. Reorganisation of mossy fiber synapses in male and female hypothyroid rats: a stereological study. J Comp Neurol 1993;337:334-52.

[25] Madeira MD, Cadete-Leite A, Andrade JP, Paula-Barbosa MM. Effects of hypothyroidism upon the granular layer of the dentate gyrus in male and female adult rats: a morphometric study. J Comp Neurol 1991;314:17186.

[26] Madeira MD, Sousa N, Lima-Andrade MT, Calheiros F, Cadete-Leite A, Paula-Barbosa MM. Selective vulnerability of the hippocampal pyramidal neurons to hypothyroidism in male and female rats. J Comp Neurol 1992;322:501-18.

[27] Montero-Pedrazuela A, Venero C, Lavado-Autric R, Fernández-Lamo I, García-Verdugo JM, Bernal J, et al. Modulation of adult hippòcampal neurogenesis by thyroid homones: implications in depressive-like behavior. Mol Psychiatry 2006;11:361-71.

[28] Pinilla L, González LC, Gaytán F, Tena-Sempere M. Oestrogenic effects of neonatal administration of raloxifene on hypothalamic-pituitary-gonadal axis in male and female rats. Reproduction 2001;121:915-24.

[29] Puymirat J. Thyroid receptors in the rat brain. Prog Neurobiol 1992;39(3):281-94.

[30] Rami A, Rabié A. Effect of thyroid deficiency on the development of glia in the hippocampal formation of the rat: an immunocytochemical study. Glia 1988;1:337-45.

[31] Rami A, Rabié A. Delayed synaptogenesisi in the dentate gyrus of the thyroid-deficient developing rat. Dev Neurosci 1990;12:398-405.

[32] Rami A, Patel AJ, Rabié A. Thyroid hormone and development of the rat hippocampus: morphological alterations in granule and pyramidal cells. Neuroscience 1986;19(4):1217-26. 
[33] Rami A, Rabié A, Patel AJ. Thyroid hormone and development of the rat hippocampus: cell acquisition in the dentate gyrus. Neuroscience 1986;19(4):1207-16.

[34] Ramos JM. Is the hippocampus necessary for spatial learning? Rev Neurol 2002;34(12):1142-51.

[35] Sala-Roca J, Martí-Carbonell MA, Garau A, Darbra S, Balada F. Effects of dysthyroidism in plus maze and social interaction tests. Pharmacol Biochem Behav 2002;3(72):643-50.

[36] Sala-Roca J, Martí-Carbonell MA, Garau A, Darbra S, Balada F. Effects of chronic dysthyroidism on activity and exploration. Physiol Behav 2002; 77:125-33.

[37] Schwegler H, Crusio WE, Lipp HP, Brust I, Mueller GG. Early posnatal hyperthyroidism alters hippocampal circuitry and improves radial-maze learning in adult mice. J Neurosci 1991;11(7):2102-6.
[38] Segal M. Dendritic spines and long-term plasticity. Nat Rev Neurosci 2005;6:277-84.

[39] Sunanda RS, Muddanna, Raju TR. Effect of chronic restraint stress on dendritic spines and excrescences of hippocampal CA3 pyramidal neurons-a quantitative study. Brain Res 1995;694:312-7.

[40] Suzuki WA. Making new memories: the role of the hippocampus in new associative learning. Ann N Y Acad Sci 2007;1097:1-11.

[41] Tohgi H, Utsugisawa K, Yamagata M, Yoshimura M. Effects of age on messenger RNA expression of glucocorticoid, thyroid hormone, androgen, and estrogen receptors in post-mortem human hippocampus. Brain Res 1995;700(1):245-53.

[42] Wooley CS, Gould E, Frankfurt M, McEwen BS. Naturally occurring fluctuation in dendritic spine density on adult hippocampal pyramidal neurons. J Neurosci 1990;10(12):4035-9. 